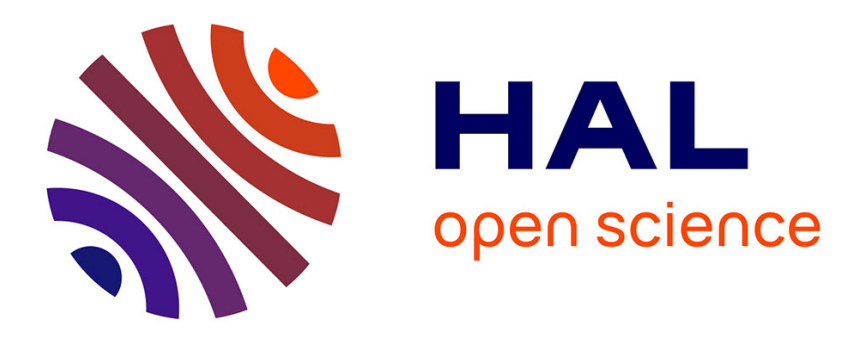

\title{
In-Plane Impact Loading of Composites : Optical Evaluation and Crack Severity Assessment for Graphite- Epoxy

\author{
F. Benitez, L. Andrades
}

\section{To cite this version:}

F. Benitez, L. Andrades. In-Plane Impact Loading of Composites: Optical Evaluation and Crack Severity Assessment for Graphite- Epoxy. Journal de Physique IV Proceedings, 1997, 07 (C3), pp.C3169-C3-174. 10.1051/jp4:1997331 . jpa-00255488

\section{HAL Id: jpa-00255488 https://hal.science/jpa-00255488}

Submitted on 1 Jan 1997

HAL is a multi-disciplinary open access archive for the deposit and dissemination of scientific research documents, whether they are published or not. The documents may come from teaching and research institutions in France or abroad, or from public or private research centers.
L'archive ouverte pluridisciplinaire HAL, est destinée au dépôt et à la diffusion de documents scientifiques de niveau recherche, publiés ou non, émanant des établissements d'enseignement et de recherche français ou étrangers, des laboratoires publics ou privés. 


\title{
In-Plane Impact Loading of Composites: Optical Evaluation and Crack Severity Assessment for Graphite- Epoxy
}

\author{
F.G. Benitez and L. Andrades \\ Department of Mechanical Engineering, University of Seville, Av. Reina Mercedes, Sevilla 41012, Spain
}

\begin{abstract}
This paper describes the test performed for the optical evaluation of propagating cracks, which assess the severity of trough cracks in composite laminates. The paper begins with the description of the experimental rig designed for dynamically loading the specimens. In particular a modified splitHopkinson pressure bar for impacts at medium range $(10$ to $30 \mathrm{~m} / \mathrm{s})$ is covered. The specimens are prepared in order to have a mirror reflective surface, by depositing aluminium, which is used to reflect a laser collimated beam in order to visualize optically the dynamic event in the crack neighborhood.

Résumé : Ce papier décrit le test réalisé pour l'observation optique de la propagation de fissures dans les composites. La configuration expérimentale est decrite, en particulier, une barre de Hopkinson modiftée pour obtenir des impacts dans le domaine de 10 a $30 \mathrm{~m} / \mathrm{s}$. Les échantillons sont préparés afin de disposer d'une surface de réflexion de type miroir, en déposant de l'aluminium. Une méchode utilisant un faisceau laser collimaté est utilisée pour observer optiquement
\end{abstract} les phénomenes dynamiques dans le voisinage de la lissure.

\section{INTRODUCTION}

Two of the most noteworthy characteristics that qualifies carbon-fiber-epoxy resin composite materials for being used in engineering applications are the high strength and stiffness per unit of weight. These two attributes make this material particularly attractive for its use in mobile structures. On the other hand, this application reveals one of the greatest clisadvantages of this material: its low strength to impact loadings and, in particular, the dificulties in detecting the damages produced by this type of loadings.

Various modes of impact damage on laninated composites exist. Low velocity impact normal to laminated panels will cause internal resin failure and delamination. The damage will cause loss of stiffness and is difficult to detect. Tougher matrix material will improve the resistance. High velocity impact norimal to the laminate will cause tear-out, with damage to a smaller part of the surrounding material. The damage resistance can be improved through use of woven fabric rather than UD material, and choosing tougher fibres such as Kevlar, where large anounts of micro failures around each filament and energy demanding fibre pull-out will absorb the impact energy, and prevent penetration. In-plane impact, as birds hitting the outer guide wanes of a jet-engine, floating objects hitting the wings of a hydrofoil boat, small pieces of pavement fired by tires during the landing or taking off of aircrafts, etc., can also cause matrix and/or fibre failure. Low velocity impact can be prevented from initiating damage by ensuring a resin rich leading edge. Damage caused by high velocity impact can be reduced by carefully choosing the fibre type and architecture (use of woven laminae versus unidirectiona or iterlaminae fibers to avoid delamination, above others). The behaviour of laminated composites is therefore desirable to characterise, and the impact resistance of these materials is important to find. This report describes a test-rig which can be used for that purpose, and how the individual parts of the apparatus are interfaced to consort. The preliminary results for in-plane impact loaded carbon/epoxy composite plates, and the efforts to make optical techniques applicable to composites by the carefull preparation of the surfaces necessary to get images of sufficiently low noise level, are also included.

Along this paper an experimental set-up) for visualizing cracks propagating under impact loads is presented. The objective is to determine crack length versus time and, from $\mathrm{it}$, to obtain the propagating speed. In addition to this we also use the set-up for monitoring strain gradients versus time by using the optical method of caustics during the dynanic process. 


\section{EXPERIMENTAL TECHNIQUES}

\subsection{Test Equipment}

The test rig is based on a standard Split-Hopkinson-Pressure-Bar (SHPB) setup, where the output bar is replaced by a specimen holder (which is not strain-gaged). The rig comprises striker bar, input bar, specimm and specimen holder (fig.1). In addition there is a compressed air reservoir for accelerating the striker bar towards the in put bar, and measuring equipment for capturing the output variables such as striker bar speed and strain waves in the input bar. By opening the quick release valve on the reservoir, the striker bar is accelerated down the barrel of the air gun. Immediately before the striker bar hits the input bar it passes through a velocity measuring device. The velocity is calculated by measuring the time between breaking two light beams of known distance. The specimen holder and the input bar form a three point bending righ where the strain wave traveling through the input bar canses an impact action-force on the specimen, and the specimen holder the two reaction-forces. The specimen is held so that the impact load causes a crack th grow from the notch towards the point of impact, and provisions are made so the specimen can be accurately aligned with the striker bar and input bar, to avoid compression-bending coupling and flexural waves in thi input bar. Two sets of gages are set on the input bar of the SHPB, so that the incident and reflected strith waves can be measurerl. From this, force vs. time plots can be made. As the specimen holder replacrs thr output bar, no transmitted strain wave can be measured. The duration of the striking pulse is function of bars length (500 mm each one).

The events were recorded using a Cordin high speed film-camera capable of capturing 500 frames at up tw 200,000 pictures per second, and a high speed video-camara with a speed of up to 40,500 pictures per second. Both systems can be used indistinct and independently for monitoring crack and caustic propagation. Fö illuminating the whole event a laser beam is used as light source, which is expanded up to a collimaled beam of $10 \mathrm{~cm}$ cliameter. The film-canera is provided with a mechanical shut ter which opens early enough previons to the time-window the event takes place and closes far after the period of interest, this forces the experiment to be carried out in darkness.

An operational amplifier with a latch up circuit is used for triggering the illumination in from the signal given by one of the photodiode used by the bar-speed measurer. The illumination is extinguised wlell a tacho signal from the film-camera is received corresponding to the instant the whole film has been fully exposed. This procedure precludes a multiple exposition of the film. The same signal that triggers thp illumination in is used for triggering the video-camera, which runs till it reaches a fixed number of image: $(16,384$ pictures $)$.

An Ion laser of 6 Watts in continuous wave was used to provide a collimated bean of single wave length ( $514 \mathrm{~nm}, 2 \mathrm{w}$.), colherent vertical polarised light. An acousto-optical cell was used to provide a means of rapid on-off switching of the laser beam, in order to expose the camera-film the correct anount of time. When this modulator is activated an amount $(9.5 \%)$ of this light (1st order beam) is bled off, throngh an iris which is lined-up with the beam-expander optics. This portion of the laser beam is then expanded to provide the required light source for the illumination of the specimen.

After illuminating the specimen by the collimated light, this is directed to a lens which focusses an imaginary plane distant $z_{o}$ from behind the specimen plane, in order to visualize a caustic created during the process of testing. This technique is used due to the specimen opacity, which forces to work under reflexion. The created image is sent to both cameras, the film-camera and the vicico-camera, by using a beam splities situated so that the reflected light from the specimen can be directed to both of them simultaneously for capturing purpose.

The test rig is clesigned to accommodate plate specimens with maximum dimensions of up to $300 \times 200 \times 30$ mm. The specimens are oparpue. In order to have a flat reflector, needed for the application of the method of caustics by reflexion, a half-a-wavelength flatness surface has to be created. Owing to the inevitable imperfections of woven composites in and near the surface, this had to be covered. The coating needs to be thin, so it does not affect the bchaviour of the composite and elastic so it follows the deflections withoul cracking. This was achieved by grinding the surface to be observerl, coating it with a thin gel-coat filu cured under pressure over a flat glass pancl to give a plane and perfectly smooth surface and claded with a layer of vapour deposited aluniniun, to obtain a reflective surface (fig.2). A distance grid in a contrating

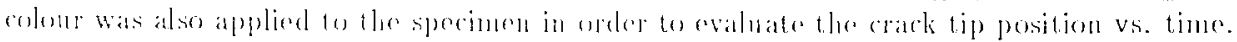




\subsection{Optical Technique}

A schematic of the optical arrangement is depicted in figure 3. To enable capture of an extended field, the laser beam must be expanded. This is obtained by passing the beam through a bi-concave lens, Ll, to give a diverging beam. The light is then passed through a bi-convex lens, L2, with a focal length function of the required light beam diameter. 'This expanded beam is deflected by a mirror, $M 1$, to illuminate the specimen. The reflected beam is converged by a bi-convex lens of a large focal distance $(3.5 \mathrm{~m})$ and send by mirror M2 to the optical recording system. After mirror M2 a beam splitter is situated which will deflect the reflected light from the specimen onto the film-camera and an image screen from which a video-camera captures the event. By positioning lens L 3 3 with respect to specimen-plane the shadow optical technique of caustics is utilized for monitoring the crack-tip caustics from which the stress-intensity factor as a function of time can be determined [1].

\subsection{Loading Technique}

When aligning the specimen in the Hopkinson-bar rig, care must be taken to ensure that the line described by the intersection of the specimen nentral plane and the crack plane is parallel and coincides with the axis of the input bar. This is to ensure a pure mode I crack growth without any flexural loading neither in the specimen nor the input bar.

After specimen, camera and optics have been set up and adjusted, cameras are started, and when the set speed is reached in the rotating drum (for film-camera), both cameras are armed. When executing the test, the camera shutter is opened immediately before the quick release valve is opened and the shutter timer set to close it shortly after. This is to minimize any unwanted stray light exposing the film.

The use of laser as the light sonrce recuires a similar procedure to the one outlined above. The acoustooptical cell is driven by a modulator which must be switclied on just before the impactor hits the specimen and off just before the film-camera begins a second exposition of the film. The camera writting time is large enough to capture the time--window through which the crack propagates. One or both cameras must be focused on the image plane rather than the specimen in order to visualize the generated caustics.

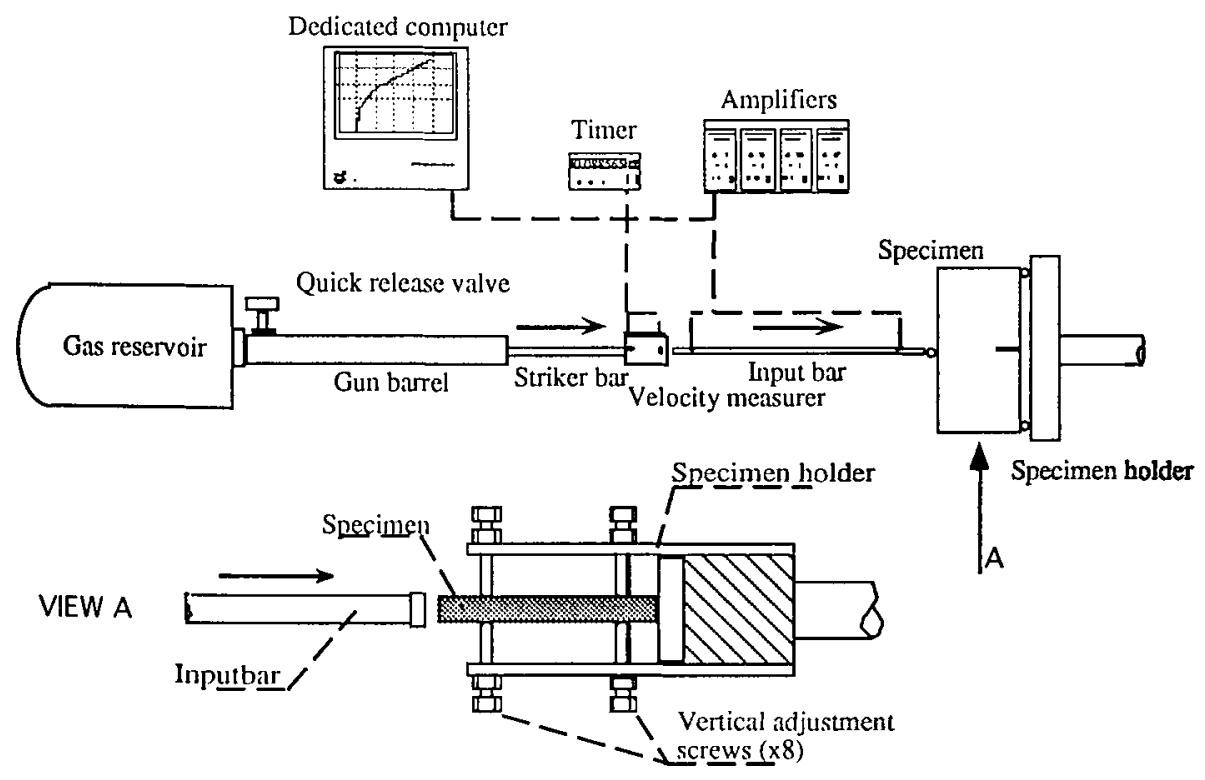

Figure 1: Schematical view of the test rig. 


\subsection{Specimens}

The specimens tested are cupons of size $125 \times 60 \times 2.5 \mathrm{~mm}$ (fig.2) from a sandwich panel, utilized for building the structure of space satellites, made of honey-combed carbon fiber-epoxy laminates. A notch length of $20 \mathrm{~mm}$ was needed to ensure a clean failure. For shorter crack-length the failure mechanism is just a penetration of the impactor without any crack propagation (fig.4). The thickness is for each laminate of the honeycomb, and the lay-up is $[02,-45,02,90,02,45] 3$ of UD Vicotec $914 / 34 \% / G 829$.
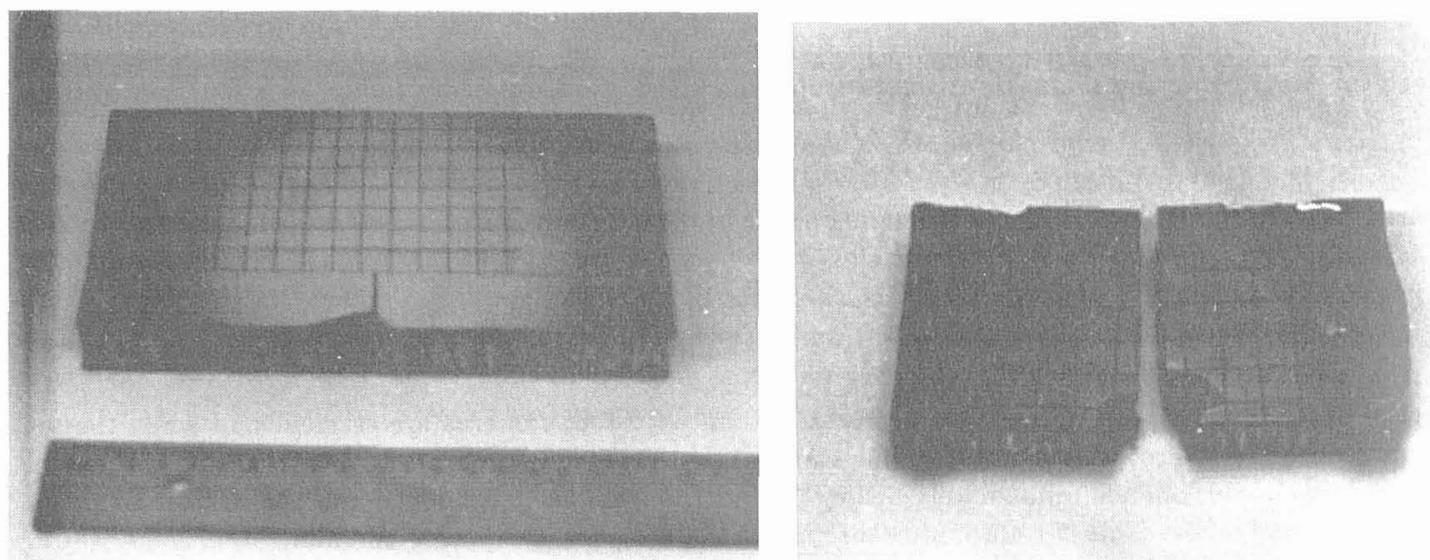

Figure 2: Honey-combed carbon fiber-epoxy laminate specimen, before and after tested.

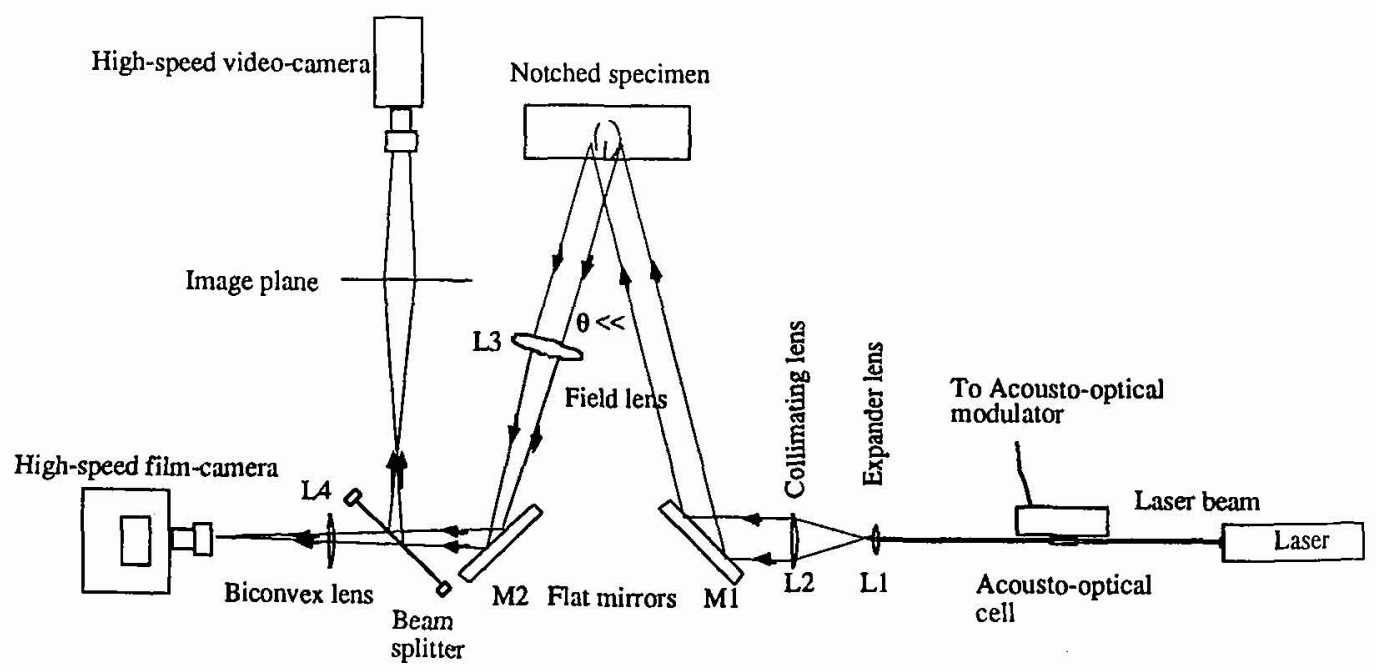

Figure 3: Schematics of the optical set-up. 


\section{RESULTS}

For tests under an impactor velocity of $30 \mathrm{~m} / \mathrm{s}$, a sequence of pictures with different time increments is shown in figure 5. At a recording rate of $175,000 \mathrm{fps}$, a crack propagation running with medium speed of the order of $100 \mathrm{~m} / \mathrm{s}$ was found (fig.6), with peaks of $250 \mathrm{~m} / \mathrm{s}$ and $400 \mathrm{~m} / \mathrm{s}$.

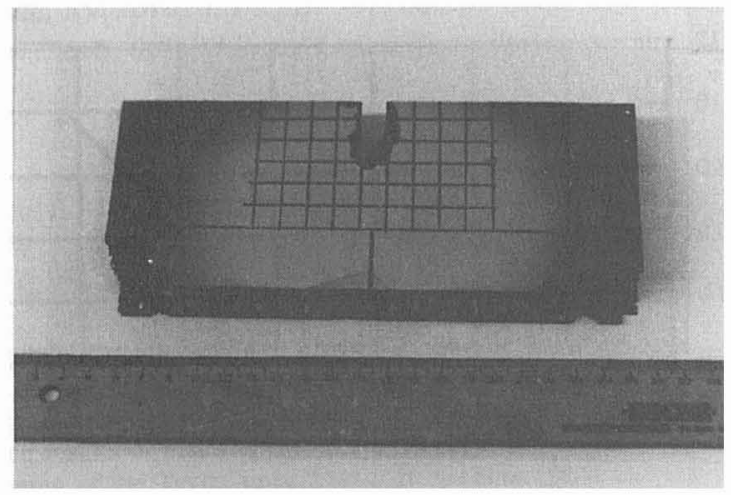

Figure 4: Failure mechanism for specimens with short cracks.
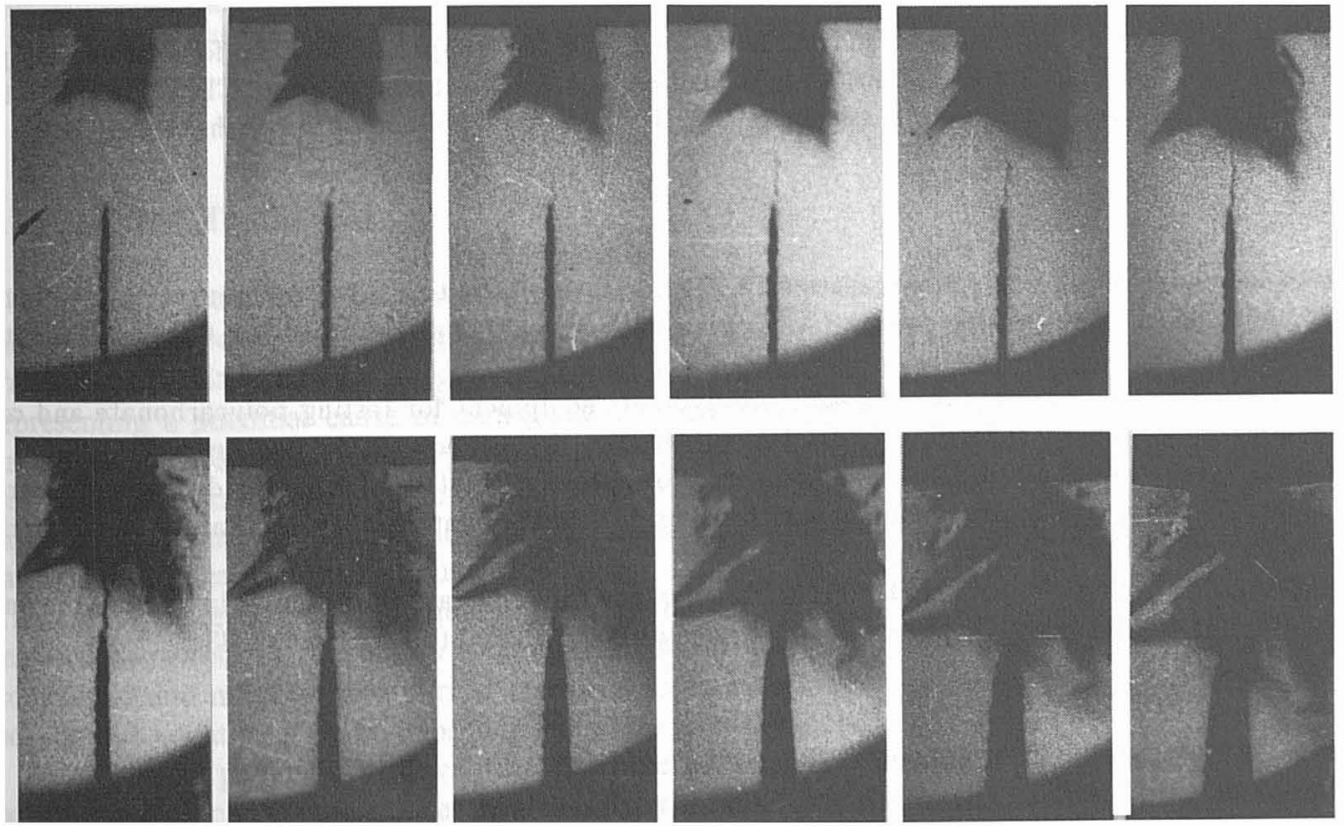

Figure 5: A propagating crack in honey-combed carbon fiber-epoxy laminate specimen. Photograms are shown in intervals of $28.5 \mu$ s (upper row) and $57 \mu$ s (lower row). 


\section{CONCLUSIONS}

Taking into account that cracks propagate in steel at speed of the order of $1000 \mathrm{~m} / \mathrm{s}$ and in PMMA of the order of $300 \mathrm{~m} / \mathrm{s}$, as average values $[2,3,4]$, we could bear in mind that for this type of structural material the mechanism of through-crack propagation is not very severe even when the crack-length is large enough. For shorter cracks (less that $30 \%$ of the specimen width) the failure mechanism precludes the propagation of any through-crack at all.

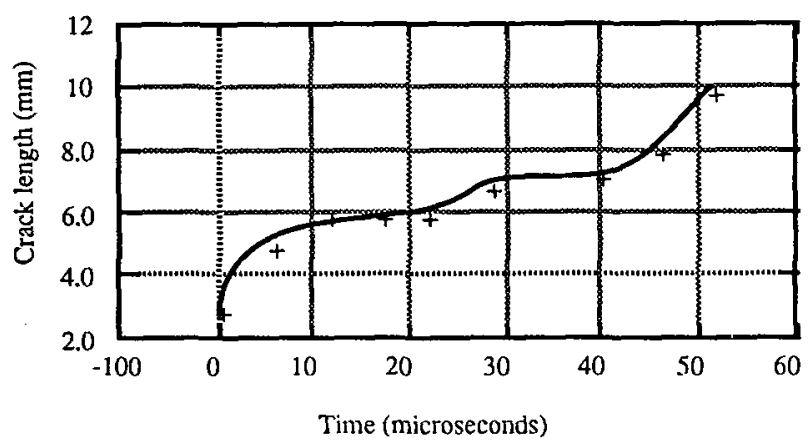

Figure 6: Crack growth in honey-combed carbon fiber-epoxy laminates.

\section{ACKNOWLEDGMENTS}

The authors thank the Space Division of CASA for providing the composite material for testing the specimens, the support of the Spanish Ministry of Education and Science through grant CICYT MAT91-1014 and the Ramon Areces Foundation for supporting the Ph.D. research of one of the authors (L.A.B.).

\section{REFERENCES}

[1] Rosakis, A.J., "Two optical techniques sensitive to gradients of optical path difference: the methorl of caustics and the coherent gradient sensor CGS". Graduate Aeronautical Laboratories, California Institute of Technology, 1991.

[2] Hognestad, G. and Benitez, F.G., "A fracture dynamic equipment for testing polycarbonate and composite materials under impact loading". Anales de Mecanica de la Fractura 11 (1995), pp. 248-25.

[3] Benitez, F.G. and Hognestad, G., "Test equipment for optical evaluation of strain field surrounding crack tips in graphite-epoxy laminates under impact loading ". ASME Joint Applied Mechanics and Materials (1995), Los Angeles CA USA, pp. 109.

[4] Hognestad, G., Pintado P. and Benitez F.G., "Equipo experimental para el estudio de la fractura din amicil en laminados de grafito-epoxy". Materiales Compuestos 95, A EMAC (1995), pp.329-334. 